\title{
Wave-induced abyssal recirculations
}

\author{
by Michael A. Spall ${ }^{1,2}$
}

\begin{abstract}
The forcing of abyssal recirculation gyres by cross-isopycnal mixing and wave fluxes near the deep western boundary is investigated. A three-layer isopycnal primitive equation model is applied in a series of experiments to an idealized basin with bottom topography. In the absence of deep western boundary current instabilities, cross-isopycnal mixing forces a cyclonic recirculation gyre, modified by topography, which is consistent with the traditional Stommel-Arons model. Instabilities of the boundary current fundamentally alter the mean basin-scale deep flow from a cyclonic recirculation to an anticyclonic recirculation. Bottom topography plays a key role in destabilizing the mean flow. The forcing mechanism for the interior recirculation is the horizontal divergence of momentum and potential vorticity fluxes carried by topographic waves that are forced by the boundary current instabilities. The strength of the recirculation gyre is linearly proportional to the kinetic energy of the waves, which is controlled in the present model by bottom drag, and well predicted by a simple scale analysis. This is essentially an adiabatic process. The addition of cross-isopycnal mixing forces the large-scale interior recirculation toward the pole, partially into boundary currents, through linear vorticity dynamics. Vorticity budgets reveal three dynamical regimes for the eddy-driven flows, the western boundary current, the recirculation region, and the interior. Similarities and differences between the mean flow and recent observations in the Brazil Basin are discussed.
\end{abstract}

\section{Introduction}

It is well known that the deep ocean circulation plays a fundamental role in the global heat budget. The abyssal circulation transports cold, fresh water that is formed at high latitudes toward low-latitudes, where it upwells to maintain the main thermocline in the presence of downward heat diffusion. It is believed that this is accomplished through a complex pattern of boundary currents and interior flows, although the dynamics, and even the path, of these flows are not well understood. The traditional view of the abyssal circulation originates from the work of Stommel and Arons (1960), whose simple model predicted that a series of deep western boundary currents exists throughout the world's oceans that carries the waters from their high-latitude regions of formation. The interior circulation in this theory consists of very weak barotropic poleward flow that feeds a broad scale upwelling

1. Institut für Meereskunde, Kiel, Germany.

2. Present address: Woods Hole Oceanographic Institution. Woods Hole, Massachusetts, 02543. U.S.A. 
into the main thermocline. However, recent basin-scale hydrographic measurements indicate that strong baroclinic flows are not confined to the region near the western boundary. There appear to exist significant large-scale recirculation gyres, crossbasin flows, eastern boundary currents, and topographic waves in the abyssal ocean (see, for example, Thompson and Luyten, 1976; Leaman and Harris, 1990; Speer and Zenk, 1993; hereafter SZ93, Durrieu de Madron and Weatherly, 1994; hereafter DW94). The presence of these currents implies that the deep ocean is influenced by higher order dynamics not included in the Stommel-Arons model, such as stratification, bottom topography, nonlinearity, and time-dependent motions. Understanding the structure and forcing mechanisms of abyssal recirculation gyres, and their relation to the deep western boundary currents and upwelling, is essential if we are to understand fully the deep ocean circulation and its role in the global climate system.

There have been a number of important theoretical developments introduced since Stommel and Arons published their pioneering work in 1960. The role of time-dependent waves and diffusion in setting up the abyssal circulation, and some influences of bottom topography, have been studied using the shallow water equations by Kawase and co-workers (Kawase, 1987; Kawase and Straub, 1991; Condie and Kawase, 1992). Rhines (1989) demonstrated that even very small topographic variations can have a controlling influence on the deep circulation, leading to closed recirculation regions, jets, and flow blocking. Influences of stratification and bottom topography were further investigated by Straub and Rhines (1990) using $1 \frac{1}{2}$ and $2 \frac{1}{2}$ layer planetary geostrophic models. Speer et al. (1993) demonstrated how large-scale variations in bottom topography and cross-isopycnal mixing can lead to the development of boundary currents and grounding in a single-layer model. Pedlosky (1992) used a simple linear model to demonstrate that zonally variable upwelling leads to baroclinic layering of the abyssal flow. Holland (1978) and Holland and Rhines (1980) (hereafter HR80) have demonstrated how instabilities in the upper ocean can drive abyssal recirculation gyres through interfacial eddy stresses. These studies have demonstrated that significant variations from the Stommel-Arons theory arise with the addition of stratification, time dependence, and bottom topography.

Many of these previous studies force the deep circulation through sources in the deep layer and a compensating upwelling into the upper ocean. This is a logical parameterization for deep basins which have no deep passages for the flow to exit. However, bottom waters do not entirely upwell in many deep basins but are instead only modified by mixing with upper deep water and remain in the form of bottom currents as they flow through narrow passages into adjacent basins. The present study is relevant to this class of problems. Important physical aspects of the model include: time dependence, primitive equation physics, stratification, bottom topography, vanishing layer thickness, and diabatic mixing. The problem is motivated by observations in the Brazil Basin, however, the application is process-oriented in nature and not intended to model the actual circulation in any particular basin. 
The model equations, forcing, and basin configuration used in this study are introduced in Section 2. The results of three experiments are briefly described in Section 3. A discussion of the dynamics, including energetics, vorticity budgets, parameter sensitivities, and comparisons with observations, are presented in Section 4. Conclusions are given in Section 5.

\section{The model}

The model used in this study is the isopycnal, primitive equation model of Bleck and Boudra (1986). The primitive equations are appropriate for problems involving steep and tall topography, highly variable layer thicknesses, cross-isopycnal fluxes, and frontal variability. For the multi-layer calculations done here this also allows for mixed baroclinic/barotropic instabilities. The isopycnal configuration of this model is particularly well suited for low vertical resolution studies which represent distinct water mass types. The parameterized "horizontal" subgridscale mixing takes place along isopycnals, as is believed to be the primary orientation of oceanic mixing. The isopycnal representation also allows for explicit control of the cross-isopycnal mixing, or diabatic heat fluxes due to unresolved mixing processes, thought to be fundamental to the deep circulation. The version of the model developed for accurate treatment of the horizontal pressure gradient in regions of tall topography and vanishing layer thickness, as described by Smith (1992), is used here.

\section{a. Dynamical equations}

The layer-integrated horizontal momentum equations are written as

$$
\begin{aligned}
\frac{\partial \mathbf{v}}{\partial t}+\nabla \frac{\mathbf{v}^{2}}{2}-(\zeta+f) \mathbf{k} \times \mathbf{v} & +\nabla_{\alpha} M \\
& =-g(\Delta p)^{-1} \Delta \tau+(\Delta p)^{-1} \nabla \cdot(A \Delta p \nabla \mathbf{v})+\left(\mathbf{v}^{*}-\mathbf{v}\right) / \gamma
\end{aligned}
$$

where $\mathbf{v}=(u, v)$ is the horizontal velocity vector, $p$ is the pressure, $\mathbf{k}$ is the vertical unit vector, $\zeta=\partial v / \partial x-\partial u / \partial y$ is the relative vorticity, $M=g z+p \alpha$ is the Montgomery potential, $\alpha$ is the specific volume of the layer (constant), $\Delta p$ is the pressure thickness of the layer, $\Delta \tau$ is the surface and bottom drag stress differences across the layer thickness, and $A$ is an eddy viscosity coefficient. An additional term has been added to the standard momentum equations that relaxes $\mathbf{v}$ toward a specified value ${ }^{*}$ with time constant $\gamma$. This forcing mechanism will be discussed in more detail later. The beta-plane approximation is used here, where $f=f_{0}+\beta y, f_{0}$ being the Coriolis parameter at the southern edge of the model domain and $\beta$ the variation of $f$ with latitude. The bottom stress is parameterized by the standard bulk method as

$$
\tau=-C_{D} \rho_{0}|\mathbf{v}| \mathbf{v}
$$


where $\mathbf{v}$ is the velocity near the bottom and $C_{D}$ is a drag coefficient. There are no interfacial stresses between model layers.

The continuity equation is represented as a prognostic equation for the layer thickness $\Delta p$,

$$
\frac{\partial \Delta p}{\partial t}+\nabla \cdot(\mathbf{v} \Delta p)+\nabla_{k} w_{i}=\left(\Delta p^{*}-\Delta p\right) / \gamma
$$

The variable $w_{i}$ represents the cross-isopycnal mass flux, and $\nabla_{k}$ indicates the divergence of this flux over the layer thickness. A positive cross-isopycnal flux represents a conversion of water mass of higher density into a water mass of lower density and thus parameterizes buoyancy forcing due to unresolved diabatic mixing processes. The diabatic processes are limited to their influence on the mass budget; momentum is not mixed across layer interfaces. For fields nearly in geostrophic balance this effect is not believed to be important as the momentum adjustment to pressure torques is dominant over diabatic forcing. The layer thickness may also be forced through a relaxation toward a specified value $\Delta p^{*}$ with time constant $\gamma$. The forcing velocity $\mathbf{v}^{*}$ is in geostrophic balance with the pressure field calculated from $\Delta p^{*}$ using the hydrostatic relation.

\section{b. Model configuration}

The model domain size, Coriolis parameter, and bottom topography have been roughly guided by the geometry of the Brazil Basin while keeping the model configuration as simple as possible. The bottom topography is shown in Figure 1; it has uniformly sloping topography from $4000 \mathrm{~m}$ to $5500 \mathrm{~m}$, a flat region in the interior, and passages through the southern and northern ridges adjacent to the western boundary. The total model domain is $3200 \mathrm{~km}$ in latitude and $2000 \mathrm{~km}$ in longitude. The east-west bottom slope is 0.002 , while the northern and southern slopes are somewhat steeper, 0.005 . In keeping with the process-oriented nature of the study, we exclude the details of an actual bottom topography such as small-scale variability, interior ridges and canyons. The northern and southern passages are not intended to represent the actual inflow and outflow dynamics, which occur in narrow passages and are probably influenced by complex mixing processes and hydraulic controls which are not included in this model. We instead force the model with a western boundary current transport and width which are typical of what is observed just downstream of the inflow region.

The model resolution was chosen to resolve distinct water masses in the vertical, the western boundary current, and the large-scale bottom topography, while remaining computationally affordable for decade-long integrations. The model has three isopycnal layers in the vertical with potential density (relative to the $4000 \mathrm{db}$ surface) $\sigma_{4}=45.70,45.94$, and 46.06 . The interface densities of 45.82 and 46.0 approximately represent the $2^{\circ} \mathrm{C}$ and $1{ }^{\circ} \mathrm{C}$ potential temperature surfaces. In the Brazil Basin, the 


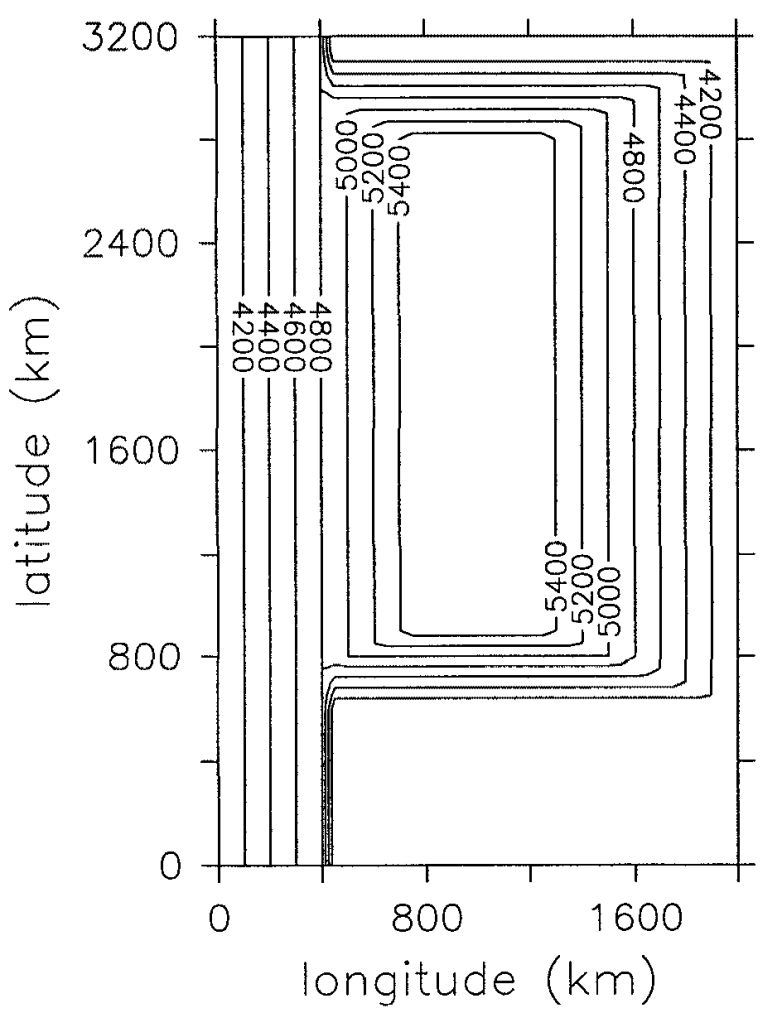

Figure 1. Model domain and bottom topography.

level of no motion between the northward flowing Antarctic Bottom Water (AABW) and the southward flowing North Atlantic Deep Water (NADW) has traditionally been taken to be close to the $2^{\circ}$ isotherm, so the sum of layers 2 and 3 approximately represents the bottom water and layer 1 represents the "upper ocean." The initial interface depths are taken to be $3600 \mathrm{~m}$ and $4300 \mathrm{~m}$ and uniform throughout the basin, thus the thickness of the deepest layer becomes zero near the perimeter of the deep basin. The grid resolution of $50 \mathrm{~km}$ resolves the western boundary current and topography quite well, and is less than the internal radius of deformation $(35 \mathrm{~km}$ to $110 \mathrm{~km}$ ) over most of the basin. The coefficient of horizontal viscosity $A=800 \mathrm{~m}^{2} \mathrm{~s}^{-1}$ for all calculations.

The model is configured as a periodic channel in the north-south direction with closed, free slip, boundary conditions on the east and west boundaries. The model is forced by the relaxation terms in the momentum and continuity equations with $\gamma=$ 10 days between 0 and $600 \mathrm{~km}$ latitude, to the south of the deep basin. This forcing allows the flow within each layer to evolve within the basin and to have physical properties and even transports at the northern outflow that are different from the southern inflow conditions, while still providing steady, uniform, specified forcing at 
the inlet to the basin. The upper layer is restored toward no flow, while between 0 and $400 \mathrm{~km}$ longitude $\mathrm{v}^{*}$ is $1 \mathrm{~cm} \mathrm{~s}^{-1}$ in layer 2 and $3.6 \mathrm{~cm} \mathrm{~s}^{-1}$ in layer 3 . The restoring velocity is zero east of $400 \mathrm{~km}$ longitude in all layers. The corresponding transports of $1.9 \mathrm{~Sv}\left(1 \mathrm{~Sv}=10^{6} \mathrm{~m}^{3} \mathrm{~s}^{-1}\right)$ in layer 2 and $4.6 \mathrm{~Sv}$ in layer 3 are within the range of estimates of the total flow of AABW into the Brazil Basin (SZ93).

One of the main motivations in using the nonphysical region between 0 and $600 \mathrm{~km}$ latitude together with periodic boundary conditions is to avoid the technical difficulties inherent in open boundary conditions. There is, of course, still the possibility of upstream and downstream influences due to the nonphysical terms outside of the basin region, however, the results have been found to be insensitive to the restoring time scale and length of the nonphysical region. We are further encouraged that the dynamical balances do not exhibit any unusual changes as one approaches the northern limit of the basin. The nonphysical region also allows for the use of periodic boundary conditions together with a meridional variation of the Coriolis parameter. The value of $f$ changes from $-0.75 \times 10^{-4} \mathrm{~s}^{-1}$ at the southern inflow $(700 \mathrm{~km}$ latitude) to $-0.25 \times 10^{-4} \mathrm{~s}^{-1}$ at the northern outflow $\left(\beta=2 \times 10^{-11} \mathrm{~m}^{-1} \mathrm{~s}^{-1}\right)$ and is then gradually restored to $-0.75 \times 10^{-4} \mathrm{~s}^{-1}$ in the nonphysical region.

An important difference between the periodic channel model used here and many other previous abyssal circulation models is that it is not required that all of the bottom water upwell into the upper ocean. We allow for the modification of bottom waters through vertical mixing of the densest bottom water mass into the upper deep water (layer 3 into layer 2), but the total transport in layers 2 and 3 that enters the basin from the south exits to the north. For a basin whose volume within each layer is not changing with time, the outflow of layer 3 at the northern exit of the basin is equal to the inflow of layer 3 at the southern entrance minus the total amount that upwelled through cross-isopycnal mixing into layer 2 . The total transport in layer 2 increases from south to north by this same amount. This is qualitatively the case for the Brazil Basin where, although there is a significant overall warming of the AABW, almost all of the AABW that flows into the basin in the south (7 Sv) is estimated to flow out to the north, either across the equator $(4.3 \mathrm{~Sv})$ or through the Romanche Fracture Zone (up to 2 Sv) (McCartney and Curry, 1993; SZ93). Of course, we do not consider multiple inflow or exit points in this idealized process study. The present configuration is most appropriate for a semi-enclosed basin at middle or low latitudes in which the vertical mixing is strongest in the deep ocean, and most of the deep water passes to an adjacent basin.

For simplicity, we will assume that the cross-isopycnal flux occurs only between layers 2 and 3. In addition to an adiabatic case with no cross-isopycnal flux, we consider an upwelling that increases with decreasing layer thickness as

$$
w_{i}=-\frac{2 g \rho_{0} K_{z}}{\left(\Delta p_{2}+\Delta p_{3}\right)}
$$


where $K_{z}=4 \times 10^{-4} \mathrm{~m}^{2} \mathrm{~s}^{-1}$ is a vertical diffusion coefficient. This parameterization will give an increase in mixing near the perimeter of the deep basin by approximately a factor of 2 as the thickness of the deepest layer vanishes due to the bottom topography. There is some evidence based on calculations by DW94 that crossisopycnal mixing rates are somewhat stronger near the western boundary than in the interior, however, the present solutions are not overly sensitive to the specific form of cross-isopycnal mixing (see Section $4 \mathrm{~b}$ ). For a total bottom water thickness representative of the basin interior $\left(\Delta p_{2}+\Delta p_{3}\right) / g \rho_{\theta}=2000 \mathrm{~m}$, this value of $K_{z}$ gives an upwelling rate of $4 \times 10^{-7} \mathrm{~m} \mathrm{~s}^{-1}$, close to the basin-averaged estimate for the Brazil Basin (SZ93, DW94). If the amount of mass to be transferred from layer 3 to layer 2 results in a negative layer thickness over a single time step, only enough mass is transferred to result in a zero thickness for the deep layer.

\section{Model results}

The results from two sets of experiments are presented, one with a stable western boundary current and one with an unstable western boundary current. We have chosen to keep the physical configuration unchanged (i.e. stratification, topography, flow strength) and stabilize the flow by increasing the bottom drag coefficient. For a value of $C_{D}=0.003$ the boundary current is unstable. This value is typical of what is generally used in ocean models and similar to the value of 0.0014 estimated over the deep slope in the North Atlantic by Grant et al. (1985). Increasing $C_{D}$ by an order of magnitude to an unrealistically large 0.03 stabilizes the flow, thereby allowing us to investigate the influences of eddy variability on the mean state under otherwise similar flow conditions and model resolution.

\section{a. Stable western boundary current, diabatic case}

The model has been integrated from a state of rest for a period of 10 years with $C_{D}=0.03$ and active cross-isopycnal mixing (called run STABLE). The mean horizontal transport streamfunction for the total transport in layers 2 and 3 is shown in Figure 2a. (The nonphysical region of the model domain is not shown.) The dominant features are the western boundary current, a basin-scale cyclonic recirculation gyre of strength $2 \mathrm{~Sv}$, and small anticyclonic gyres near the northern and southern boundaries. The western boundary current broadens slightly from south to north in the basin. The viscous drag at the bottom slows the deep western boundary current, and the zonal pressure gradient forces a flow down the topographic slope into the basin interior. The interior of the deep basin is spun up by information being advected in a cyclonic sense approximately along the closed geostrophic contours with some modification due to the cross-isopycnal mixing and friction. The spin-up mechanism of edge waves dispersing into long Rossby waves discussed by Kawase (1987) is not effective in layer 3 (where most of the transport is carried) because the 
(a) STABLE

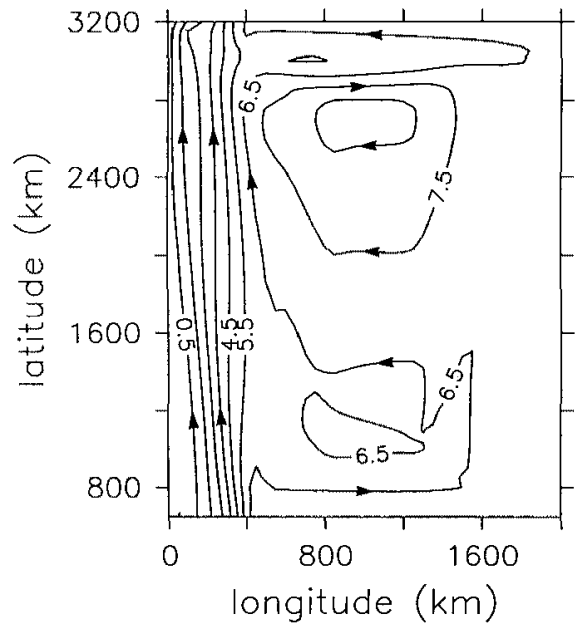

(b) UNSTABLE

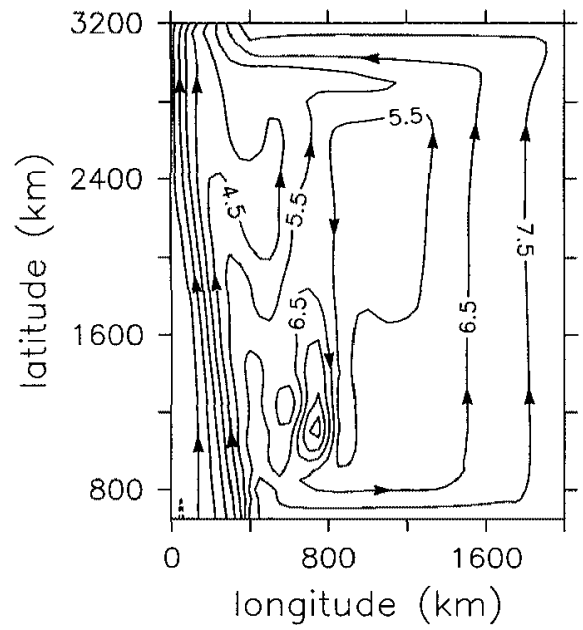

(c) ADIABATIC

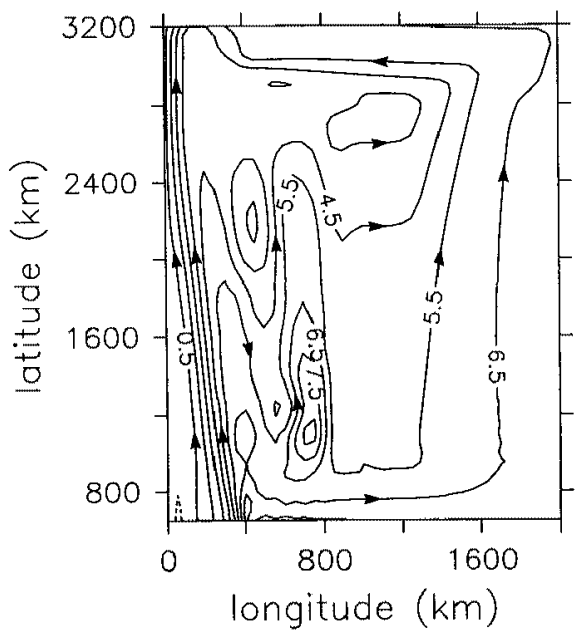

Figure 2. Mean transport streamfunction (Sv) for layers $2+3$. (a) STABLE, stable western boundary current $\left(C_{D}=0.03\right)$ with cross-isopycnal mixing, (b) UNSTABLE, unstable western boundary current $\left(C_{D}=0.003\right)$ with cross-isopycnal mixing, (c) ADIABATIC, unstable western boundary current $\left(C_{D}=0.003\right)$ with no cross-isopycnal mixing.

deep basin consists of closed geostrophic contours and is thus inaccessible to Rossby waves (Straub and Rhines, 1990; Kawase and Straub, 1991). The model is essentially void of any time-dependent motion.

\section{b. Unstable western boundary current, diabatic case}

Decreasing the bottom drag coefficient results in the growth of instabilities along the western boundary current. The model has been integrated from a state of rest for 
a period of 10 years with $C_{D}=0.003$ and nonzero cross-isopycnal mixing (UNSTABLE). An approximate steady state is reached in about 5 years. The mean horizontal transport streamfunction for the sum of layers 2 and 3 is shown in Figure $2 \mathrm{~b}$, calculated over the final 5 years of integration. The dominant features represented in the mean flow are the western boundary current, a tight cyclonic recirculation gyre along $700 \mathrm{~km}$ of longitude, and an anticyclonic basin-scale recirculation gyre. The western boundary current becomes somewhat narrower and shoals to the west as it moves toward the equator, qualitatively similar to the hydrographic sections reported by DW94. The cyclonic recirculation gyre exists where the sloping bottom meets the flat interior. It is strongest in the south (approximately $3 \mathrm{~Sv}$ ) and extends approximately $1000 \mathrm{~km}$ toward the north. The basin-scale anticyclonic recirculation gyre is in opposite sense to that found with a stable western boundary current, and has a maximum transport of $2 \mathrm{~Sv}$. We note here that in the eastern basin the depth-integrated flow is nearly parallel to the bottom topography over the eastern slope.

The imposed cross-isopycnal mixing rate results in a uniform decrease in the total northward transport in the deepest layer from $5.6 \mathrm{~Sv}$ at the southern inflow to $2.8 \mathrm{~Sv}$ at the northern outflow, while the transport in layer 2 increases by the same amount from $1.9 \mathrm{~Sv}$ to $4.5 \mathrm{~Sv}$. The associated warming of the deep water is qualitatively similar to the water mass transport changes with latitude reported by McCartney and Curry (1993).

\section{c. Unstable western boundary current, adiabatic case}

The influence of cross-isopycnal mixing is indicated by a low bottom drag run $\left(C_{D}=0.003\right)$ with no cross-isopycnal flux (ADIABATIC). The mean transport streamfunction shown in Figure $2 \mathrm{c}$ shows the same basic features found in run UNSTABLE. The main difference is that the basin-scale recirculation gyre is now slightly stronger and northern intensified, rather than being carried primarily near the boundaries. The general influence of the diabatic flux is to force parcels to the south through the linear vorticity balance (see next section). The forcing of the anticyclonic recirculation gyre itself, however, is shown by this result to be a fundamentally adiabatic process.

\section{Discussion}

\section{a. Dynamics}

Three distinct dynamical regimes in the basin are revealed by considering the time averaged vorticity equation, following the approach of Boudra and Chassignet (1988). Two modifications to their analysis are introduced. Because the form of the nonlinear terms in the momentum equation used here does not formally conserve enstrophy (a constraint given up when allowing for vanishing layer thickness), the nonphysical "conservation" terms discussed by Boudra and Chassignet are no longer 


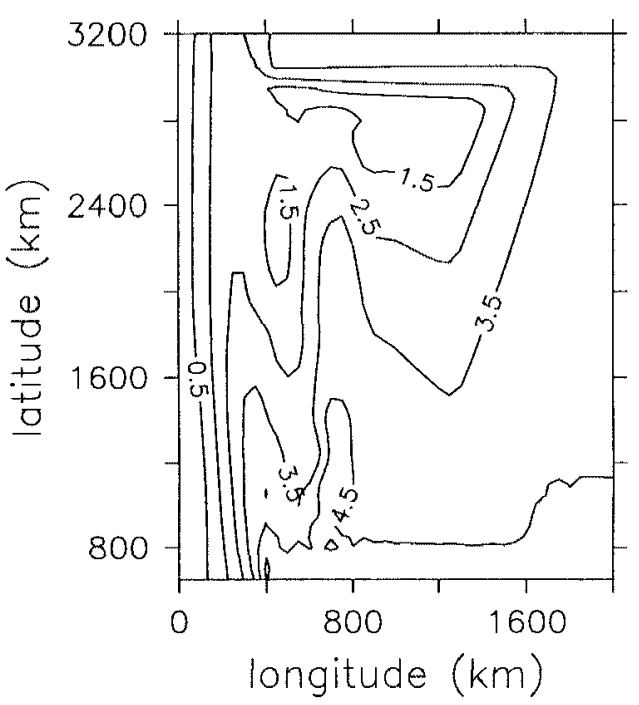

Figure 3. Transport streamfunction in Sv in layer 3 for run ADIABATIC.

present. Each of the terms in the continuous relative vorticity equation has a corresponding relation when derived from the finite difference form of the momentum equations, and there are no residual terms. Secondly, we distinguish between the mean and eddy contributions, when appropriate. The continuous form of the relative vorticity equation is written as

$$
\begin{aligned}
\frac{\partial \zeta}{\partial t}=-\mathbf{v} \nabla \zeta-\beta v-(\zeta+f) \nabla \mathbf{v}- & k[\nabla \alpha \times \nabla p] \\
& +A \mathbf{k}\left[\nabla \times\left(\frac{\partial p}{\partial s}\right) \nabla \cdot\left(\frac{\partial p}{\partial s} \nabla \mathbf{v}\right)\right]-g_{\rho_{0}} C_{D}|\mathbf{v}| \zeta / \Delta p .
\end{aligned}
$$

This equation may also be written symbolically as

$$
\text { DZDT }=\text { ADV + BETA + STR + SOLEN + VISC + DRAG } .
$$

This balance states that the time rate of change of relative vorticity (DZDT) is forced by (1) horizontal advection of relative vorticity (ADV), (2) horizontal advection of planetary vorticity (BETA), (3) stretching (STR), (4) the solenoidal or twisting term (SOLEN), (5) the viscous stress curl (VISC), and (6) bottom drag (DRAG). For a sufficiently long model integration such that the fields have reached a statistical equilibrium (DZDT $=0$ ), the nonlinear terms ADV and STR may be further divided into mean (MADV and MSTR) and eddy (EADV and ESTR) contributions.

Each of the terms in (5) has been calculated for layer 3 over the final 5 years of the ADIABATIC model integration. The mean streamfunction for layer 3 is shown in Figure 3. There is an anticyclonic circulation of more than $3 \mathrm{~Sv}$ in the basin interior. 


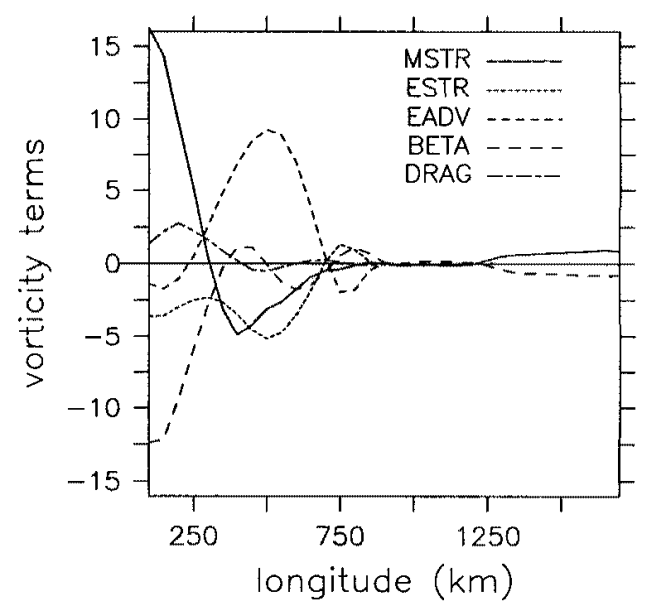

Figure 4. Terms in the mean relative vorticity Eq. (6) for run ADIABATIC. Units of $10^{-13} \mathrm{~s}^{-2}$.

The deep western boundary current and meandering pattern over the slope in the west are similar to what was found in the total transport for layers 2 and 3 . There is a small decrease in total northward transport within layer 3 with increasing latitude (the $4.5 \mathrm{~Sv}$ contour intersects the eastern boundary). This is because the deep layer is not quite in equilibrium, it is still gaining a little mass as it adjusts to the initial and boundary conditions. The rate of increase is largest during the first 1-2 years of integration, however, the system is nearly in balance over the time period of the analysis, the final 5 years of integration. There is a corresponding decrease of mass in layer 2 so that total mass in the basin is conserved.

Integrating the terms in the vorticity equation around closed streamlines can nearly eliminate the mean terms (to within numerical interpolation errors) and reveal the net influence of the remaining terms on the circulation within the closed region, as demonstrated by HR80. However, as indicated in Figure 3, very few of the mean streamlines in the deep layer close upon themselves, most enter and exit the domain through the southern and northern boundaries. The mean streamlines also pass through several distinct dynamical regimes as they transit the model domain, a feature that would be difficult to demonstrate using an integrated approach. The key aspects of the balances are most clearly revealed through the meridional averages of the terms as a function of longitude as shown in Figure 4. The terms are only weakly dependent on latitude so the basic balances are well represented by this average. Terms MADV, VISC, SOLEN, and the residual due to time dependence are negligible and thus not shown.

The dominant balance of terms in the western boundary current (longitude $<350 \mathrm{~km}$ ) is between mean stretching, beta, and bottom drag, with some contribution from eddy stretching. This is the traditional western boundary current balance. The change in planetary vorticity experienced as parcels are carried toward 
the equator is compensated for by a decrease in layer thickness and, to a lesser extent, by loss of vorticity at the bottom. The influence of bottom drag is largest near the equator because the current accelerates to the north as the fluid columns are compressed.

The recirculation region $(350 \mathrm{~km}<$ longitude $<750 \mathrm{~km})$ indicates a balance primarily between stretching (MSTR and ESTR), eddy flux of relative vorticity (EADV), and advection of planetary vorticity (BETA). The largest term, EADV, is due to the Reynolds stresses, suggesting that eddy fluxes will play an important role in connecting the deep western boundary current to the basin interior. The mean and eddy stretching terms indicate a general broadening of the flow to the south. Although bottom drag is important for the energy balance in this region, it does not show up in the vorticity balances due to the symmetry of the waves.

The interior region (longitude $>750 \mathrm{~km}$ ) has a simple balance between mean stretching (MSTR) and advection of planetary vorticity (BETA). This is expected for the weak steady interior flow and is consistent with linear vorticity dynamics.

i. Conditions for instability: the source of the eddy fluxes. The broad, relatively weak, bottom intensified deep western boundary current forced through the southern boundary in the present model has a cross-flow gradient of the mean potential vorticity that is everywhere negative. Over a flat bottom, this type of flow is linearly stable to small perturbations. However, the inclusion of bottom topography can destabilize a mean flow that would otherwise be stable. This results from the lower boundary condition contribution to the integrated energy equation. Pedlosky (1980) demonstrated this influence by considering a mean flow with zero cross-flow potential vorticity gradient. The resulting necessary condition for instability requires that, for a bottom slope $\alpha$,

$$
\frac{N^{2} \alpha}{f}+\frac{\partial U}{\partial z}=0
$$

somewhere in the domain. This is equivalent to requiring that the isopycnals are parallel to the bottom topography somewhere in the region. Pedlosky further demonstrates that the unstable modes of such a system can have the same dispersion relation as the bottom trapped topographic waves discussed by Rhines (1970), suggesting that energy may be radiated away from the unstable current in the form of topographic waves.

The instability condition may be rewritten in terms of the required shear between model layers 3 and 2 as

$$
U_{3}-U_{2}=\frac{g^{\prime} \alpha}{f}
$$




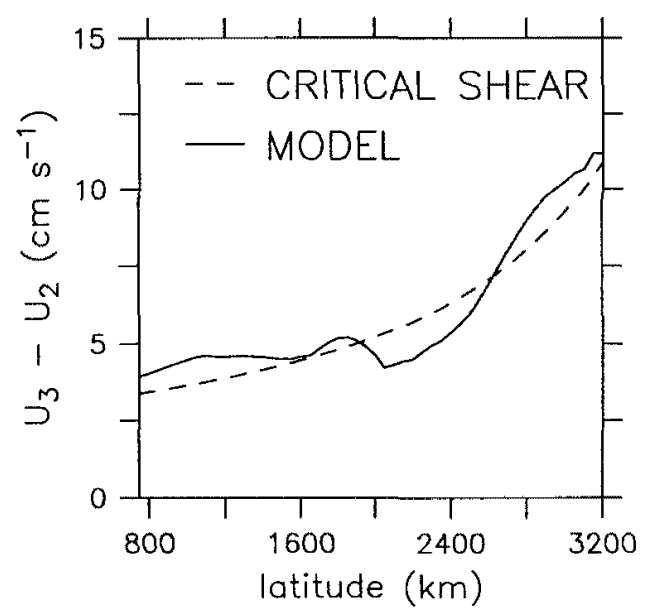

Figure 5. Maximum mean vertical shear in model run ADIABATIC (solid line) together with the vertical shear necessary for baroclinic instability (dashed line).

The maximum mean vertical shear at each latitude in model run ADIABATIC is shown in Figure 5, along with the critical vertical shear given by (8). The model shear is quite close to the shear required for instability over the entire latitude range of the basin. The vertical shear becomes large as the equator is approached due to the decrease in $|f|$. This result indicates that the model instability is caused by the sloping bottom. Furthermore, it suggests that the instability mechanism acts as a limiting influence on the maximum shear that can be supported in the western boundary current. As the shear increases to the critical level, the boundary current becomes unstable and radiates energy (in the form of topographic waves) until the boundary current is stabilized again.

Hydrographic sections shown by DW94 clearly demonstrate that the AABW isopycnals are parallel to the bottom topography, and thus the necessary conditions for instability are met, at SAVE sections 1, 2, and 3 (latitudes 10S, 18S, 25S) in the Brazil Basin. There is also an increase in the observed vertical shear at lower latitudes, consistent with (8).

ii. The recirculation region: influence of the eddy fluxes. The introduction of instabilities into the western boundary current was seen to alter the mean circulation on the basin scale in a fundamental way. The cyclonic gyre predicted by the Stommel-Arons model is replaced by an anticyclonic recirculation, although both circulations obey the linear vorticity equation in the basin interior. We now investigate the role of the time dependent motion near the western boundary region in driving the basin scale mean circulation.

The primary function of the sloping bottom near the western boundary is to 

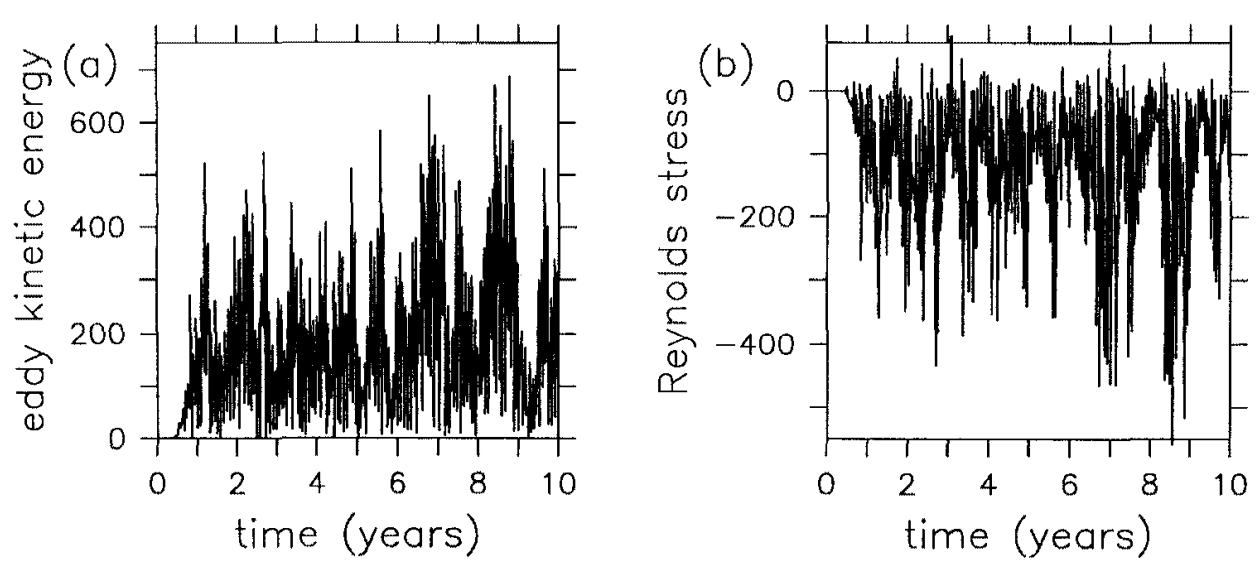

Figure 6. Time series of (a) eddy kinetic energy $\left(\mathrm{cm}^{2} \mathrm{~s}^{-2}\right)$ and (b) Reynolds stress $\left(\mathrm{cm}^{2} \mathrm{~s}^{-2}\right)$ at $450 \mathrm{~km}$ longitude, $2000 \mathrm{~km}$ latitude for run ADIABATIC.

provide a destabilizing influence on the mean flow and a medium for the generation and propagation of stratified topographic waves (Rhines, 1970), which may carry information from the western boundary current into the interior. For topographic waves in the southern hemisphere with horizontal scales larger than the deformation radius, the phase speed along the western boundary is toward the north. For an energy source to the west, the energy must propagate to the east, hence the waves must have a westward phase speed. For long waves in the southern hemisphere, this requires that the zonal and meridional wavenumbers be of the opposite sign, or that the Reynolds stress $\left(-\overline{u^{\prime} v^{\prime}}\right)$ be negative. Thus long waves which propagate energy offshore and to the south would have phase speeds onshore and to the north.

iii. Energetics. The nature of the variability in ADIABATIC is indicated in Figure 6a by the time series of kinetic energy at a point to the east of the mean western boundary current over the sloping bottom. The variability is dominated by two characteristic frequencies. A high frequency variability occurs with a period of 32 days while a lower frequency variability indicates the passage of energetic events about once every year. The energy level of these pulses varies but generally peaks at about $300-500 \mathrm{~cm}^{2} \mathrm{~s}^{-2}$, indicating maximum bottom velocities on the order of $20 \mathrm{~cm} \mathrm{~s}^{-1}$. The Reynolds stress time series (Fig. 6b) shows negative peaks which correspond closely with the energetic pulses. This is the signature of topographic waves with downslope energy propagation. Inspection of the horizontal layer thickness or relative vorticity fields indicates that these events are due to the passage of wave packets, characterized by wavelengths of $400 \mathrm{~km}$ with phase speeds to the north and west. The high frequency oscillation of 32 days is consistent with the topographic wave dispersion relation and the orientation of the waves. The time scale between 


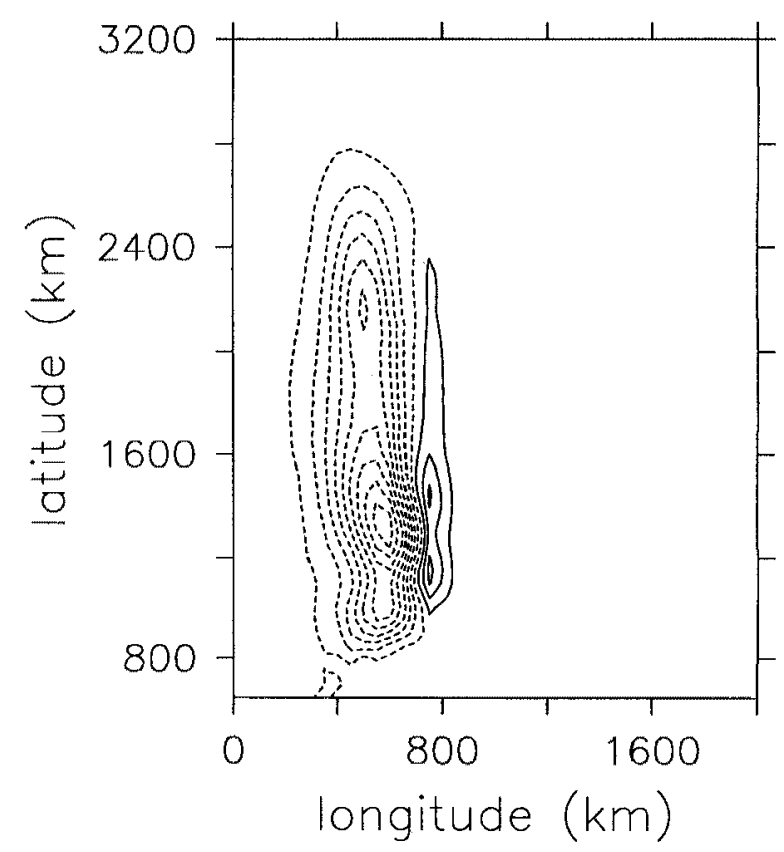

Figure 7. Depth averaged Reynolds stress $\left(-\overline{u^{\prime} v^{\prime} h}\right)$ for layer 3 over the final 5 years of model integration ADIABATIC $\left(10^{5} \mathrm{~m} \mathrm{~cm}^{2} \mathrm{~s}^{-2}\right)$.

packets of waves is determined by the time it takes for the western boundary current instabilities to grow to finite amplitude and radiate waves.

The depth averaged Reynolds stress $\left(-\overline{u^{\prime} v^{\prime} \Delta p}\right)$ in layer 3 based on the final 5 years of run ADIABATIC is shown in Figure 7. There is a gradual increase in amplitude from the western boundary to approximately $600 \mathrm{~km}$ longitude, and then a more rapid decrease between $600 \mathrm{~km}$ and $800 \mathrm{~km}$, where the sloping bottom topography meets the flat interior. A very similar pattern is also found for eddy kinetic energy because $u^{\prime} \approx v^{\prime}$. The downslope variation of the Reynolds stresses indicates that the momentum flux carried by the waves is horizontally divergent. The offshore change in Reynolds stress between 0 and $600 \mathrm{~km}$ longitude indicates that more northward momentum is fluxed to the east by the waves than is supplied from the west. This leads to a northward momentum deficit and will thus tend to force a southward mean flow over the broad topographic slope. Similarly, the offshore increase in Reynolds stress between $600 \mathrm{~km}$ and $800 \mathrm{~km}$ longitude will tend to force a narrow northward flow. This is qualitatively similar to what we find in the mean transports in Figure $2 \mathrm{~b}$ and $c$. The offshore increase in Reynolds stress and eddy kinetic energy indicates that the topographic waves generated at the western boundary current are unstable as they propagate into the interior (i.e. the amplitude is growing in time, following the group velocity of the wave). This is consistent with the theoretical calculations of Pedlosky (1980). 


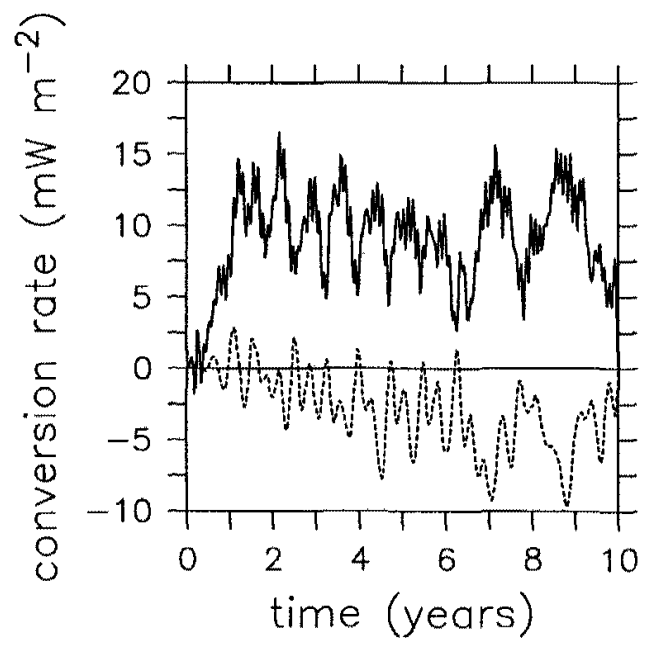

Figure 8. Energy conversion rates $\left(\mathrm{mW} \mathrm{m}^{-2}\right.$ ) averaged over the basin interior (longitude $>400 \mathrm{~km}$ ) for run ADIABATIC. Solid line is the conversion from potential energy to eddy kinetic energy, dashed line is the conversion of eddy kinetic energy to mean kinetic energy (this term has been multiplied by a factor of 100 ).

This wave instability is demonstrated in the model by calculating the conversion rates between mean and eddy components of kinetic energy and potential energy, following the method of Onken (1992). The conversion of potential energy to eddy kinetic energy averaged over the interior of the model domain (longitude $>400 \mathrm{~km}$ ) is shown in Figure 8 as a function of time; positive values correspond to a conversion of potential energy to eddy kinetic energy. This is the signature of wave instabilities, with strong pulses taking place about once per year. The timing of the conversion events is consistent with the peaks in kinetic energy found in the time series in Figure 6. The source of the large kinetic energy over the sloping bottom is the potential energy of the waves. The dashed line in the figure is the conversion rate from mean kinetic to eddy kinetic energy by the Reynolds stress terms. The negative peaks shown here correspond to a conversion of eddy kinetic energy into the mean kinetic energy of the flow; in other words, the eddy fluxes are driving the mean recirculation gyres in the interior. The timing of the peaks corresponds closely to the wave radiation events. The scale factor of 100 is as expected for the relatively weak amplitude of the recirculation gyre $\left(1 \mathrm{~cm} \mathrm{~s}^{-1}\right)$ compared to the wave amplitude $\left(10 \mathrm{~cm} \mathrm{~s}^{-1}\right)$.

iv. Potential vorticity considerations. We make use of the time average potential vorticity equation to understand the role of the topographic waves in driving the mean circulation in the interior. Rhines and Holland (1979) derived a turbulent Sverdrup balance which relates the eddy flux of potential vorticity to the mean flow 


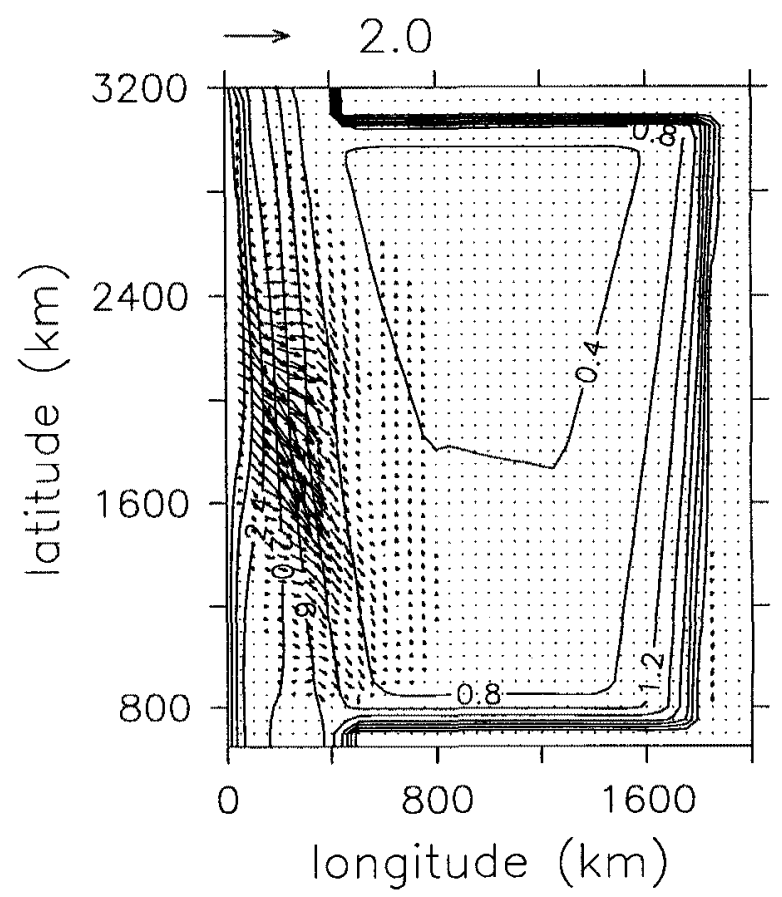

Figure 9. Eddy flux of potential vorticity in layer $3\left(10^{-9} \mathrm{~s}^{-2}\right)$ superimposed on the mean potential vorticity $\left(-10^{-7} \mathrm{~m}^{-1} \mathrm{~s}^{-1}\right)$ for run ADIABATIC.

across the mean potential vorticity gradient as

$$
\mathbf{U} \cdot \nabla Q=-\nabla \cdot\left(\overline{\mathbf{u}^{\prime} q^{\prime}}\right)
$$

where $\mathbf{U}$ is the mean velocity, $Q=f / H$ is the mean potential vorticity, $\mathbf{u}^{\prime}$ is the perturbation velocity, $q^{\prime}=\left(f+v_{x}^{\prime}-u_{y}^{\prime}\right) / h$ is the perturbation potential vorticity, $h$ is the thickness of the isopycnal layer, and $H$ is the time mean layer thickness. This expression is most valid for nearly inviscid, adiabatic motions where the horizontal scale of the parcel trajectories (over the dissipation time scale) is much less than the scale over which the mean potential vorticity varies. The first two assumptions are well met here, but the third is not because the bottom topography varies significantly over the wavelength of the topographic waves, and topography controls the mean potential vorticity gradient for the deep layer. Although this formal approximation is not well satisfied, it will be shown that (9) is essentially valid, and provides a very useful relationship for understanding the source and the strength of the anticyclonic recirculation.

The eddy flux of potential vorticity in layer 3 calculated from run ADIABATIC is shown in Figure 9, superimposed on the mean potential vorticity contours. The potential vorticity of the deepest layer is controlled by the topography, with a slight 
increase toward the north due to the beta effect. The meridional eddy flux of potential vorticity is downgradient everywhere while the zonal eddy flux is upgradient (potential vorticity increases toward the interior, and toward the north). The flux is largest over the middle of the slope and at approximately the middle latitude of the basin. HR80 and Thompson (1994) find downgradient eddy potential vorticity fluxes in the deep ocean for deep recirculation gyres driven by instabilities in the upper ocean, with nearly compensating upgradient fluxes in the upper ocean. HR80 showed that the downgradient flux was dominated by the vertical stresses, while the lateral stresses were upgradient. Haidvogel and Rhines (1983) find both upgradient and downgradient potential vorticity fluxes in a variety of dynamical regimes, notably regions of outward energy radiation had upgradient fluxes. The source of eddy fluxes in the present model is in the deep ocean rather than the upper ocean, and the eddy flux is dominated by horizontal stresses, rather than by the vertical stresses that drive abyssal recirculations from upper ocean instabilities. In addition, the unstable topographic waves have a net outward kinetic energy flux as they propagate into the interior. In the previous works, the kinetic energy of the eddies decreases away from the source due to damping by friction.

The eddy potential vorticity flux may also be related to an effective diffusivity (Rhines and Holland, 1979) as

$$
K_{i i}=-\frac{\left(\overline{u_{i}^{\prime} q^{\prime}}\right)}{\frac{\partial Q}{\partial x_{i}}} .
$$

The effective zonal diffusivity calculated from (10) is everywhere negative over the slope, with a maximum amplitude of $-3.5 \times 10^{6} \mathrm{~cm}^{2} \mathrm{~s}^{-1}$. The meridional diffusivity is positive and approximately twice as large as the zonal diffusivity, up to $7 \times 10^{6} \mathrm{~cm}^{2} \mathrm{~s}^{-1}$.

Eq. (9) indicates that the mean flow generated by the eddy fluxes is determined by the divergence of the eddy potential vorticity flux and the mean potential vorticity gradient. The zonal and meridional divergences of the eddy potential vorticity fluxes are shown in Figure 10a and b. The zonal flux divergence is positive in the western boundary current and negative over the sloping bottom east of approximately $200 \mathrm{~km}$. The sign of the zonal gradient of the mean potential vorticity is everywhere positive, so that the induced mean zonal motion will be of opposite sign to the zonal flux divergence. Thus, within the western boundary current the induced mean zonal flow is to the west, while over the slope east of the western boundary current the eddy forced mean zonal flow is toward the east. The meridional flux divergence, Figure 10b, shows alternating bands of negative and positive values, while beta causes the meridional gradient of the mean potential vorticity to be positive. The eddy fluxes will tend to accelerate the western boundary current toward the north and west and force a meandering eastward mean flow over the sloping topography. These trends are in general agreement with the mean transport streamfunction for layer 3 shown 

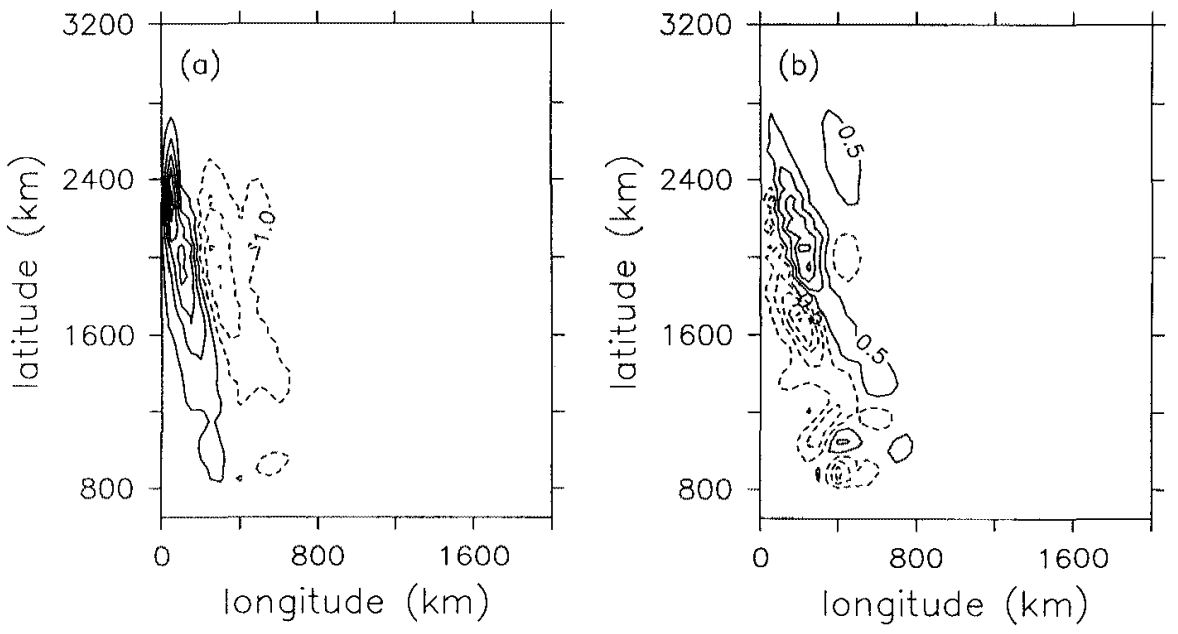

Figure 10. Horizontal divergence of the eddy potential vorticity flux $\left(10^{-15} \mathrm{~s}^{-2}\right)$ for run ADIABATIC (a) zonal divergence (contour interval $=2.0$ ), (b) meridional divergence (contour interval $=1.0$ ).

in Figure 3. Once out of the region of active eddy fluxes, the flow approximately follows geostrophic contours, as discussed further in the next section. The interior recirculation gyre is forced by the zonal flow directed from the western boundary region into the basin interior, although the sense (cyclonic versus anticyclonic) is not determined by the eddy forcing near the western boundary. It will be shown in the next section that the Mid-Atlantic ridge provides compression that forces the flow to turn northward and results in an anticyclonic circulation.

A quantitive estimate of the strength of the offshore flow, and thus the strength of the recirculation gyre in the absence of upwelling, is now obtained. Given knowledge of the eddy potential vorticity flux, and noting that it varies over the same horizontal scales as the mean potential vorticity field, the mean zonal velocity is approximated as

$$
U=\frac{\left(\overline{u^{\prime} q^{\prime}}\right)}{Q} .
$$

For the present calculations, $\overline{u^{\prime} q^{\prime}}=\mathscr{O}\left(10^{-9} \mathrm{~s}^{-2}\right)$ and $Q=\mathscr{O}\left(10^{-7} \mathrm{~m}^{-1} \mathrm{~s}^{-1}\right)$, giving $U=$ $\mathscr{Q}\left(10^{-2} \mathrm{~m} \mathrm{~s}^{-1}\right)$, which is in agreement with the model results. However, we may go further and relate the eddy potential vorticity flux to the eddy kinetic energy by approximating the perturbation potential vorticity $q^{\prime}=\left(v_{x}^{\prime}-u_{y}^{\prime}\right) / h \approx 4 u^{\prime} / \lambda H$, where $\lambda$ is the wavelength of the wave. The strength of the recirculation gyre $(\Gamma)$ is given by $\Gamma=U H L_{y}$, where $L_{y}$ is the meridional distance over which the eddy fluxes are active. We may now derive an estimate for the strength of the recirculation gyre 
driven by eddy fluxes over the sloping western bottom as

$$
\Gamma=\frac{4 u^{\prime 2} H L_{y}}{f \lambda} .
$$

This estimate indicates that the strength of the recirculation is linearly dependent on the kinetic energy of the waves and the area over which the wave fluxes act, and increases for shorter wavelength waves and at lower latitudes. Because the recirculation occurs along open, rather than blocked or closed streamlines, it is not dependent on, or limited by, the frictional effects in the model. This is in contrast to the scaling given by Rhines and Holland (1979) and Thompson (1994) for closed and blocked trajectories.

A series of calculations in which the bottom drag was varied between 0.001 and 0.008 have been carried out to test the above scaling estimate. The variation of bottom drag is used to control the strength of the waves, or $u^{\prime}$ in the above scaling. This allows us to demonstrate the influence of wave energy, or potential vorticity flux, on the strength of the recirculation, and also to show that the bottom drag does not constrain the strength of the recirculation, other than indirectly through damping the waves. The kinetic energy was calculated over the final 5 years of integration. To get a representative value over the meridional length scale $L_{y}$, the kinetic energy was averaged between $800 \mathrm{~km}$ and $2300 \mathrm{~km}$ latitude (the range where the eddy fluxes are most active, $L_{y}=1500 \mathrm{~km}$ ). The maximum value of the meridionally averaged kinetic energy was used in the scaling estimate. In each of the calculations, the maximum kinetic energy was found near $500 \mathrm{~km}$ longitude, where the mean layer thickness is approximately $700 \mathrm{~m}$ ( $H$ above). The Coriolis parameter was chosen as the average value over the latitude range of $800 \mathrm{~km}$ to $2300 \mathrm{~km}\left(-0.6 \times 10^{-4} \mathrm{~s}^{-1}\right)$. Figure 11 shows the strength of the anticyclonic recirculation gyre in model layer 3 as a function of the kinetic energy of the waves for various values of bottom drag. There is very nearly a linear dependence whose slope agrees quite closely with the scaling estimate (12). The maximum value of $C_{D}=.008$ has nearly eliminated the topographic waves and, in the absence of any wave energy, the anticyclonic recirculation gyre disappears. Setting the bottom drag to zero resulted in numerical instability, however, reducing the bottom drag by $50 \%$ from .002 to .001 only resulted in an increase of the wave energy and strength of the recirculation of less than $10 \%$.

This result indicates that the turbulent Sverdrup balance is valid in the eddy flux region and that the potential vorticity flux carried by the waves controls the strength of the interior recirculation gyre. This confirmation of the role of eddy fluxes is found here for a different range of parameter space than reported by previous investigators. The eddy fluxes are carried primarily by lateral stress terms, not vertical stresses, with the source of eddy variability being in the deep ocean. In addition, the mean potential vorticity field is controlled by the bottom topography and varies significantly over the horizontal scale of the waves. The forcing of interior flows through 


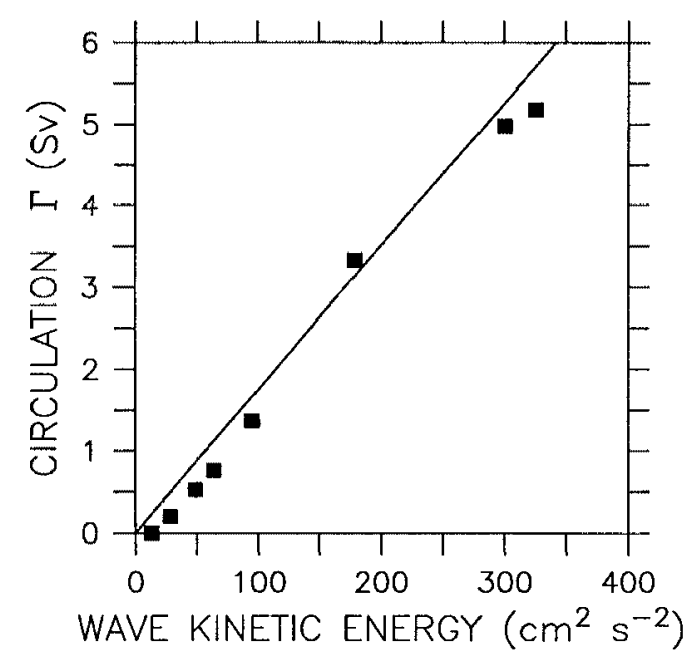

Figure 11. Strength of the anticyclonic recirculation gyre (Sv) as a function of wave kinetic energy. The symbols are taken from a series of model calculations with values of the bottom drag increased uniformly from 0.001 (upper right symbol) to 0.08 (lower left symbol). The solid line is the estimated strength of the recirculation based on scaling estimate (12) and the wave kinetic energy in the model.

the intersection of geostrophic contours with energetic regions was suggested by Rhines and Holland (1979). Kawase and Straub (1991) anticipated that regions of closed geostrophic contours might be spun up by horizontal eddy fluxes carried by waves, although a particular source of the variability, or the direction of the mean flow, was not specified. They also anticipated that topographic waves would replace Kelvin waves as a means for rapid propagation of information in a stratified basin with sloping topography near the side walls. Hogg (1993) showed that a parameterization of the eddy potential vorticity flux near the Gulf Stream could force large-scale cyclonic and anticyclonic recirculation gyres to the north and south of the stream consistent with observations.

v. The interior region. The previous analysis demonstrated how the eddy flux of potential vorticity drives the anticyclonic gyre in the basin interior for the case with no cross-isopycnal mixing. We will now consider the dynamics of the basin interior for two cases with cross-isopycnal mixing, one with an unstable western boundary current (UNSTABLE) and one with a stable western boundary current (STABLE). The basic role of the eddy fluxes in forcing the anticyclonic recirculation is not influenced by the addition of cross-isopycnal mixing. We consider the diabatic cases here in order to contrast the eddy-driven flows with the more traditional StommelArons recirculation and also in order to make some comparisons with observations in the Brazil Basin. 

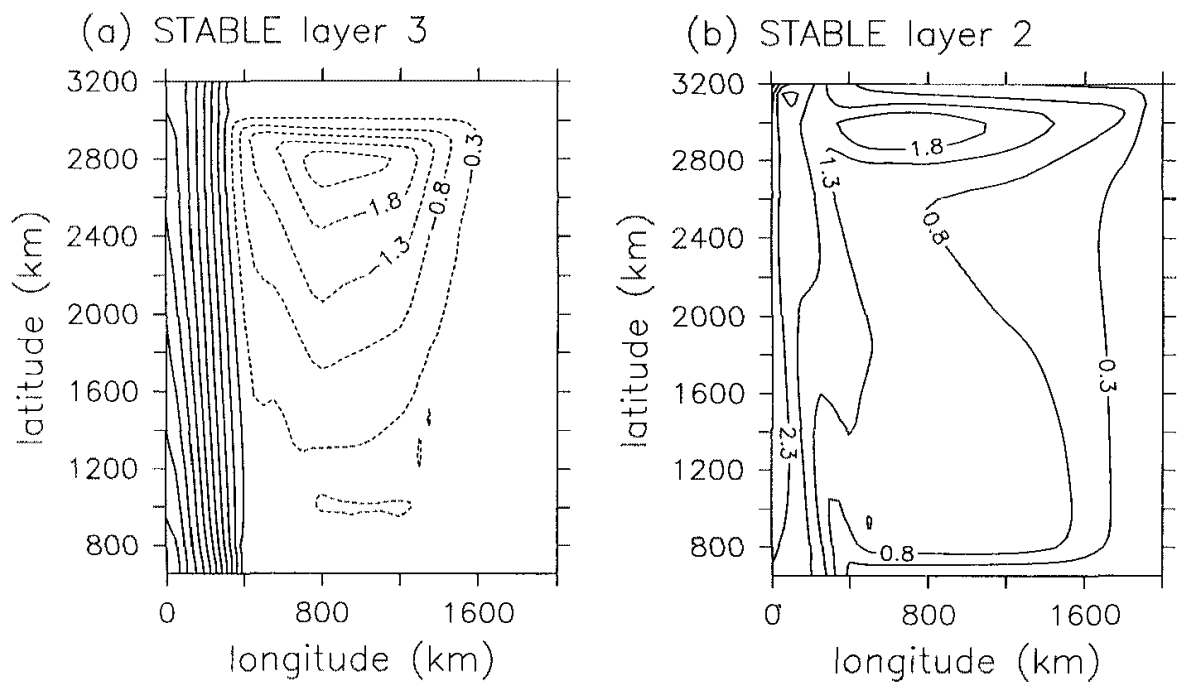

Figure 12. Meridional transport (Sv) relative to the eastern boundary for run STABLE (a) layer 3, (b) layer 2.

The dynamics of the interior circulation are most easily revealed if we consider the flow in layers 3 and 2 separately. The meridional transport in layer 3 of run STABLE, relative to the eastern boundary, is shown as a function of latitude in Figure 12a, negative values indicate a net southward flow. This quantity is different from a transport streamfunction because with nonzero cross-isopycnal mixing the flow is horizontally divergent (note the decrease in total northward transport in layer 3 with latitude). The circulation is dominated by the western boundary current and an interior cyclonic recirculation gyre. The cyclonic gyre has a maximum strength of $3 \mathrm{~Sv}$ and is the type of circulation predicted by the Stommel-Arons model with modifications due to the sloping bottom. The interior flow is governed by the linear vorticity equation

$$
\beta v=f w_{z}
$$

In the interior of the basin the vertical velocity at the flat bottom (between $800 \mathrm{~km}$ and $1200 \mathrm{~km}$ longitude) is zero, and at the top of the abyssal layer it is positive $\left(w_{z}>0\right)$ therefore, in the southern hemisphere the meridional flow must be to the south. The change in $f$ with latitude is reflected by a more southward-directed flow at higher latitudes. The upward-sloping bottom near the eastern boundary (MidAtlantic ridge) results in an increased vertical divergence compared to that in the interior, because $w<0$ at the bottom, and thus drives a stronger southward flow. West of $800 \mathrm{~km}$ longitude the flow up the topography is strong enough to reverse the sign of the vertical divergence $\left(w_{z}<0\right)$ and results in a northward meridional velocity to close the recirculation. A similar cyclonic recirculation within geostrophic 
(a) UNSTABLE layer 3

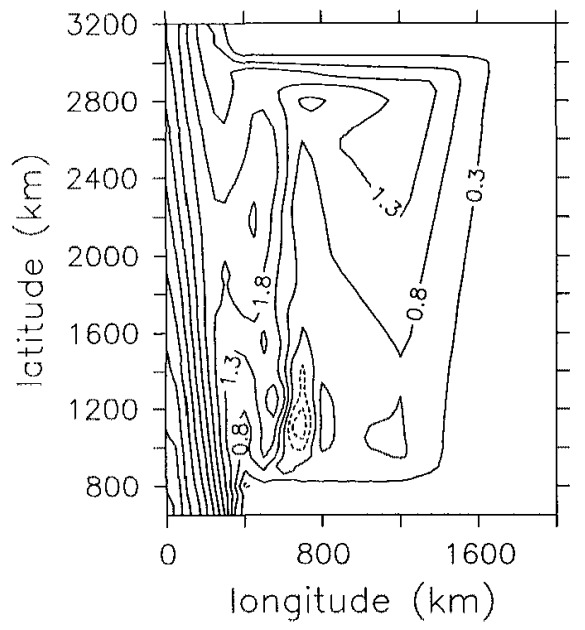

(b) UNSTABLE layer 2

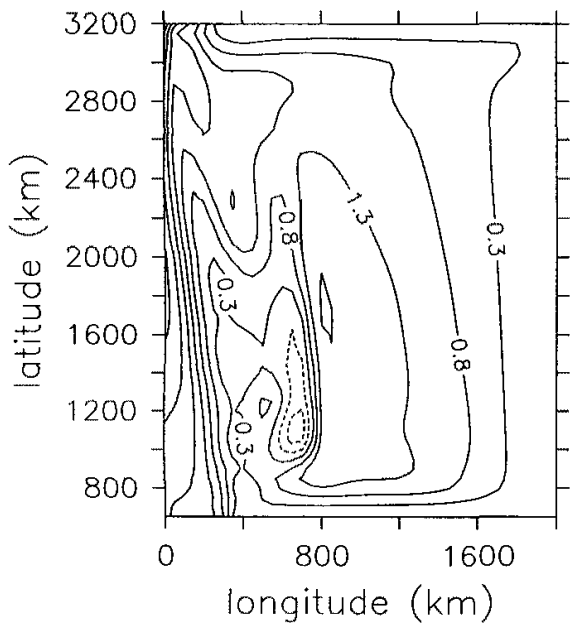

Figure 13. As in Figure 4 for run UNSTABLE.

contours closed by topography and forced by upwelling is reported by Kawase and Straub (1991) and Kawase (1993).

The meridional transport for layer 2 is shown in Figure 12b. Most of the transport supplied to the basin interior comes from the southern boundary current. For an interior isopycnal layer that mixes more strongly with the deep water than with the upper ocean, such as is the case here and, on basin average, in the Brazil Basin, the vertical divergence will be negative and thus must be compensated for by a flow toward the equator. The variation of the Coriolis parameter with latitude decreases $v$ toward the north and forces the flow to turn to the west in the interior.

The northern and southern recirculation gyres found in STABLE and UNSTABLE are driven by the boundary-enhanced cross-isopycnal mixing. Horizontal gradients in cross-isopycnal fluxes result in horizontal pressure gradients because regions of increased mixing will have deeper isopycnal depths. For vertical mixing which is inversely proportional to layer thickness, this will result in a depressed interface near the boundaries and thus will drive a flow with deep water on the left. The width of the current is determined by the horizontal scale of the topography. The tight recirculation gyre found to the north in run STABLE is required to supply the northern boundary current.

The meridional transport in layer 3 for run UNSTABLE is shown in Figure 13a. The sense of the deep flow in the interior is now anticyclonic with maximum strength $1.5 \mathrm{~Sv}$, in opposite direction to what was found in the absence of western boundary current instabilities. The strength of the deep recirculation is less than for run ADIABATIC because of cross-isopycnal mixing into layer 2 . The flow enters the interior of the basin from the west, both in a southern boundary current and in a 
broad eastward flow. This eastward transport is forced by the eddy flux of potential vorticity, as discussed in the previous section. In the interior over the flat bottom the flow is toward the south and east, as required by the linear vorticity equation. The flow abruptly turns to the north at $1200 \mathrm{~km}$ longitude as it encounters the region of decreasing depth. The topographic interaction results in a positive vertical velocity at the bottom of magnitude greater than the upwelling velocity between layers 2 and 3 , making the vertical divergence negative and forcing the flow to the north. It is this influence of the bottom topography that forces the large-scale flow to be anticyclonic. Calculations with the Mid-Atlantic ridge topography removed show that the largescale flow is toward the pole everywhere in the interior (in a cyclonic sense) as expected based on linear vorticity dynamics. The interior of layer 2 (Fig. 13b) flows to the north and west and is supplied by the southern boundary current, similar to run STABLE and consistent with linear vorticity dynamics. The northern recirculation gyre is now much weaker as a result of the reversal of the direction of flow in the deep layer.

The bottom topography, baroclinicity, and mixing play important roles in closing the basin-scale recirculation gyre in an anticyclonic sense in run UNSTABLE by forcing the compression of fluid columns in the eastern basin of the deep layer. This interaction of the baroclinic mode with the bottom may be masked in the presence of cross-isopycnal mixing if one considers only the total transport of bottom water (Fig. $2 b)$ because the integrated transport flows parallel to the bottom topography. This depth-integrated flow appears to violate the linear vorticity equation because the vertical divergence would be zero for flow parallel to the topography, yet the meridional flow is to the north. It is only when one considers the baroclinic structure that we detect the vortex compression supplied at the bottom maintained by the east-west overturning mode.

\section{b. Parameter sensitivities}

The waves which are responsible for forcing the recirculation gyres are driven by baroclinic instability of the western boundary current over the sloping bottom. For topographic slopes in the range found in the deep Brazil Basin, results similar to those discussed here are obtained. If the bottom slope under the western boundary current is increased to 0.004 , or made flat, the flow is stabilized because there is no correct vertical shear in the western boundary current to satisfy (7). For these cases the Stommel-Arons type recirculation is recovered. The role of friction was discussed in the previous section, primarily through its influence on the wave energy. While these results demonstrate the dependence of the recirculations on the wave fluxes, they also indicate that this mechanism is relatively sensitive to the model configuration. We note, however, that the eddy fluxes carried by the waves need only occur over a portion of the western boundary, not over its entire length. Thus meridional variations in the topographic slope may confine instability and topographic wave 
resonance to a subregion of the western boundary, however this would still be sufficient to spin-up an interior recirculation gyre.

The mechanism discussed here works in the northern hemisphere in the same way, it is not sensitive to symmetric reflection about the equator. The general application of these ideas to other physical configurations and basins will, of course, depend on the local stability characteristics of the western boundary current and its ability to force topographic waves. For example, while the steeper topographic slopes under the North Atlantic Deep Water boundary current in the North Atlantic would introduce a stabilizing influence, the vertical shear of that boundary current is much stronger than for the AABW studied here, which may be sufficient to destabilize the flow. The hydrographic section of the deep western boundary current in the North Atlantic shown by Pickart (1992) indicates that the necessary condition for instability is met, although other sections appear to be stable. Each case would have to be investigated independently to assess the resonant coupling of the boundary current to ambient topographic waves.

Further increases in the amplitude of the cross-isopycnal flux do not qualitatively change the results; they only result in a larger transfer of mass from layer 3 into layer 2. The addition of a weaker cross-isopycnal flux between layer 2 and layer 1 (mixing of deep water with the upper ocean) does not significantly change the results presented here. Uniform upwelling of $4 \times 10^{-7} \mathrm{~m} \mathrm{~s}^{-1}$ between layers 2 and 3 gives results similar to UNSTABLE, although the boundary currents and anticyclonic recirculation gyre are slightly weaker.

Computational expense prohibits calculations at higher horizontal resolution. However, identical calculations have been carried out at lower resolution $(80 \mathrm{~km})$ and, with the exception of a decrease in strength of the cyclonic recirculation gyre near the western topography, are essentially the same as those reported here. It is expected that higher resolution would result in stronger and more complex recirculations adjacent to the western boundary, but that the basic forcing mechanism and basin-scale anticyclonic recirculation will remain unchanged.

\section{c. Relevance to observations}

There have been several recent studies devoted to mapping out the large-scale flow structure in the Brazil Basin as part of the World Ocean Circulation Experiment (WOCE) Deep Basin Experiment, for example SZ93 and DW94. Schematics of the total bottom water transport from both SZ93 and DW94 are reproduced here in Figure 14. The common feature is a basin-scale anticyclonic recirculation gyre of several Sverdrups adjacent to the northward flowing western boundary current. The flow pattern of DW94 is somewhat more complicated than SZ93 and, in particular, indicates two bifurcations of the deep currents and a cyclonic gyre in the deep northern part of the basin. The present modelling study is very idealized in nature and is not intended to predict details of the observed flow in the Brazil Basin. 

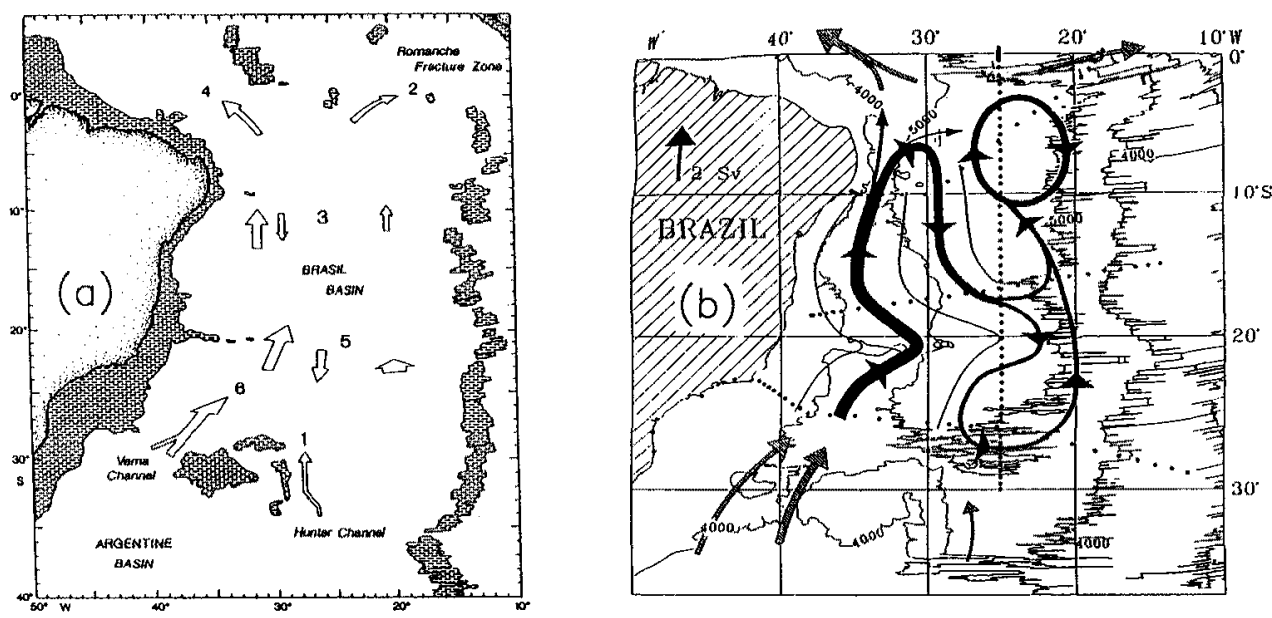

Figure 14. Schematic diagrams of the transport of Antarctic Bottom Water based on hydrographic sections, reproduced from (a) Speer and Zenk (1993) and (b) Durrieu de Madron and Weatherly (1994).

Nonetheless, the anticyclonic recirculation gyre produced in the low viscosity model calculations is similar in strength and distribution to those in Figure 14. The model also produces bifurcations of the deep western boundary flows near $2200 \mathrm{~km}$ and $1600 \mathrm{~km}$ latitude.

The main differences between the model results and the transport schematics are the lack of a tight cyclonic recirculation gyre in the southwestern domain in the observations and the absence of a cyclonic gyre in the deep northern basin in the model. The tight recirculation in the model is due to wave fluxes at the abrupt change in topographic slope; it is possible that a more gradual change would result in a weaker recirculation. Calculations with intermediate values of bottom drag produce a cyclonic gyre in the northern part of the deep layer in addition to the basin scale anticyclonic gyre, however, it is much weaker than that reported by DW94. This may be due to several factors including: idealized bottom topography, simple crossisopycnal mixing distribution, and limited vertical resolution.

The South Atlantic Ventilation Experiment (SAVE) section 6 at 25W shows several features which are similar to those produced in run UNSTABLE. The depth of the $\sigma_{4}=46.0$ at the center of the model domain running from south to north is shown in Figure 15a. The main features are the broad eastward flow in the deep basin (layer interface deepens to the south in the interior), net eastward transport in the deep layer due to cross-isopycnal mixing in the eastern basin, and northern and southern boundary currents. The SAVE 6 section (Fig. 15b) also indicates a broad eastward flow in the deep basin. DW94 calculated a total eastward transport in the deep layer $\left(\sigma_{4}>46.01\right)$ of $1-2 \mathrm{~Sv}$ with a compensating westward return flow in the upper AABW, similar in amplitude and structure to that found in the model. The 

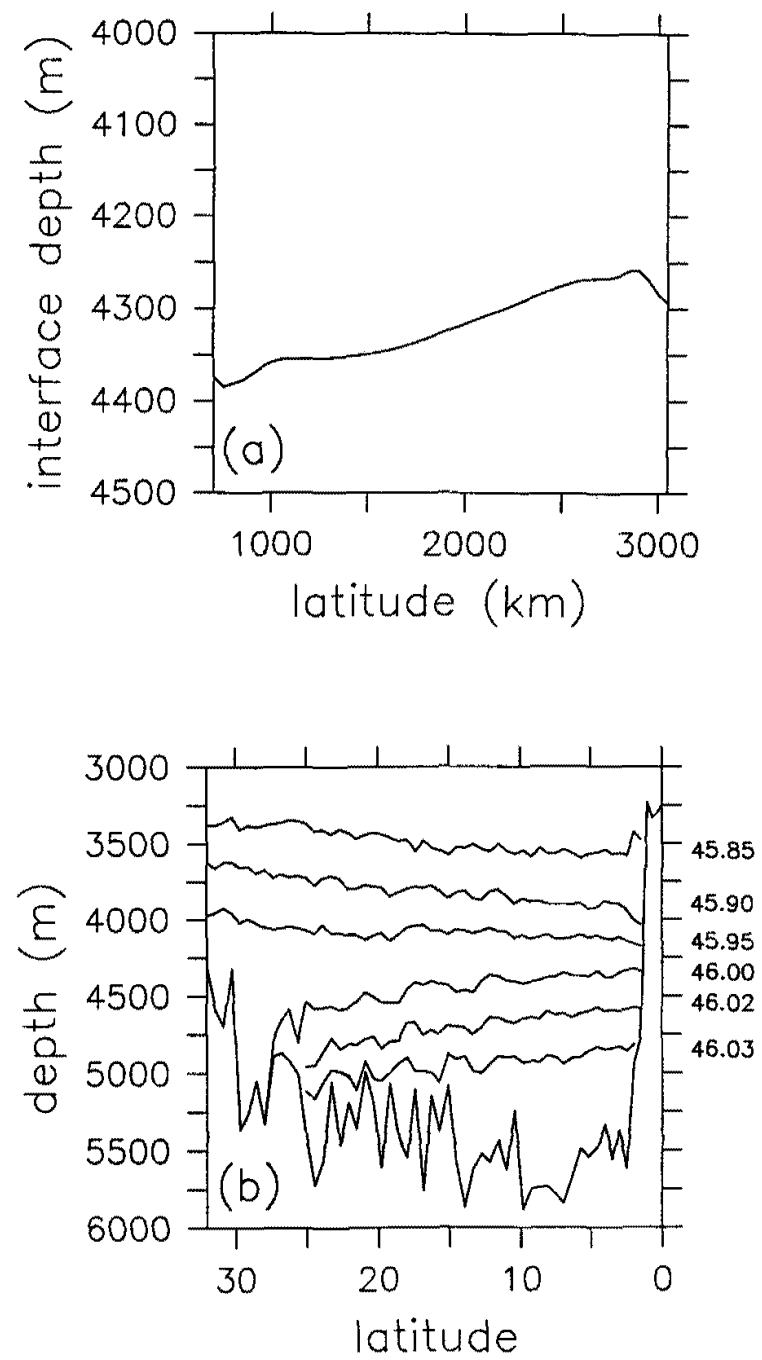

Figure 15. (a) Depth of the $\sigma_{4}=46.0$ for model run UNSTABLE. (b) Potential density anomaly $\left(\sigma_{4}\right)$ from SAVE section 6 at $25 \mathrm{~W}$.

observed eastward flow in the deep basin implies that some cross-isopycnal mixing must be taking place because there is no abyssal exit for this water. This suggests that the vortex compression supplied by the Mid-Atlantic ridge found in the model (eastward flow into a region of decreasing layer thickness) may support the observed northward flow of AABW near the Mid-Atlantic ridge in the anticyclonic recirculation gyres of DW94 and SZ93. There is also a net shallowing of the interface from south to north across the basin and some indication of northern and southern 
boundary currents in the hydrography, although it is difficult to calculate a geostrophic velocity at the northern limit of the basin because of its proximity to the equator.

The key feature to determine if eddy fluxes near the western boundary might be responsible for the observed basin-scale anticyclonic recirculation gyre would be the presence of topographic waves consistent with downslope energy propagation. The place to look for the topographic waves would be east of the western boundary current over the sloping bottom, somewhere near $15 \mathrm{~S}, 30 \mathrm{~W}$. Although the period of the waves is short, of order 1 month, the waves in the model are intermittent in nature, with peaks occurring only about once per year. Hence, one would want to look for the waves over a period of at least one year and possibly two years to get reliable energy flux estimates. Mooring arrays which are currently deployed as part of the WOCE Deep Basin Experiment may provide the answer. Preliminary analysis of current meter data near the Santos Plateau and the Vema Channel indicate the presence of bottom trapped waves with periods near 30 days.

\section{Summary}

The interaction of a deep western boundary current and a semi-enclosed deep basin has been investigated. For a stable western boundary current with basin-scale cross-isopycnal mixing, the basin interior flow is dominated by a cyclonic recirculation gyre, consistent with the traditional Stommel-Arons dynamics with modifications due to bottom topography. When instabilities of the western boundary current are permitted to grow, the resulting eddy fluxes are found to alter fundamentally the direction of the large-scale deep circulation from cyclonic to anticyclonic. The bottom topography provides a destabilizing influence on the mean flow, consistent with previous theoretical results. Perturbations along the unstable boundary current take the form of topographic waves, which are able to propagate energy and potential vorticity downslope into the basin interior. The divergence of the eddy potential vorticity flux forces a mean zonal flow into the basin interior. Once out of the region of strong eddy forcing, the flow approximately follows the geostrophic contours around the deep basin interior in an anticyclonic sense. The Mid-Atlantic ridge, together with the eastward flow, provides compression to form the anticyclonic circulation and close the flow to the north. A simple scaling estimate based on a turbulent Sverdrup balance in the eddy flux region indicates that the strength of the recirculation is linearly dependent on the kinetic energy of the waves. This is essentially an adiabatic process. The inclusion of cross-isopycnal mixing broadens the structure of the basin-scale gyre toward the south, partially into boundary currents, through linear vorticity dynamics. The large-scale characteristics of the recirculation gyre when eddy fluxes and cross-isopycnal mixing are included compare favorably with the large-scale hydrography in the Brazil Basin.

We have made a number of simplifying assumptions and the results are no doubt quantitatively sensitive to these choices. The underlying mechanism of the eddy- 
mean flow interaction, however, results most strongly from the instability of the boundary current, and the ability of topographic waves to flux energy and potential vorticity into the interior. It remains to be seen how the inclusion of realistic features, such as ridges, canyons, and roughness, as well as a more sophisticated mixing parameterization and the presence of NADW, may influence the results found here.

Acknowledgments. This work was started while MAS was at the Institut für Meereskunde in Kiel, Germany and supported by the Bundesminister für Forschung und Technologie Grant \#03F0050D. Final analysis and revisions were carried out at the Woods Hole Oceanographic Institution under support from National Science Foundation Grant OCE-9301323. Rainer Bleck and Linda Smith are thanked for providing the original primitive equation model and helpful suggestions with regard to the cross-isopycnal formulation and forcing the model. A vorticity analysis routine provided by Eric Chassignet was the starting point for the analysis used in this paper. Rainer Onken provided some computing facilities and the analysis routine for the calculation of the energy conversion terms. Kevin Speer, Walter Zenk, Xavier De Madron and Georges Weatherly kindly provided preliminary copies of their figures used in Figure 14. Xavier De Madron and Georges Weatherly also provided the isopycnal depths along the SAVE section 6 shown in Figure 10b. Two thorough reviews prompted a more detailed analysis of the potential vorticity balances and the role of the eddy fluxes. I would like to thank everyone at the Institut für Meereskunde, and Drs. Gerold Siedler and Walter Zenk in particular, for making my visit both enjoyable and rewarding. This is contribution number 8556 from the Woods Hole Oceanographic Institution.

\section{REFERENCES}

Bleck, R. and D. B. Boudra. 1986. Wind-driven spin-up in eddy-resolving ocean models formulated in isopycnic and isobaric coordinates. J. Geophys. Res., 91(C), 7611-7621.

Boudra, D. B. and E. P. Chassignet. 1988. Dynamics of Agulhas retroflection and ring formation in a rumerical model. Part I: The vorticity balance. J. Phys. Oceanogr., 18, $280-303$.

Condie, S. A. and M. Kawase. 1992. Models of abyssal flow in basins separated by a mid-ocean ridge. J. Mar. Res., 50, 421-440.

Durrieu de Madron, X. and G. Weatherly. 1994. Circulation, transport and bottom boundary layers of the deep currents in the Brazil Basin. J. Mar. Res., 52, 583-638.

Grant, W. D., A. J. Williams III and T. F. Gross. 1985. A description of the bottom boundary layer at the HEBBLE site: low-frequency forcing, bottom stress, and temperature structure. Mar. Geol., 66, 219-241.

Hadivogel, D. B. and P. B. Rhines. 1983. Waves and circulation driven by oscillatory winds in an idealized ocean basin. Geophys. Astrophys. Fluid Dyn., 25, 1-63.

Hogg, N. G. 1993. Toward parameterization of the eddy field near the Gulf Stream. Deep-Sea Res., 40, 2359-2376.

Holland, W. R. 1978. The role of mesoscale eddies in the general circulation of the ocean-numerical experiments using a wind-driven quasi-geostrophic model. J. Phys. Oceanogr., 8, 363-392.

Holland, W. R. and P. B. Rhines. 1980. An example of eddy-induced ocean circulation. J. Phys. Oceanogr., 10, 1010-1031.

Kawase, M. 1987. Establishment of deep ocean circulation driven by deep water production. J. Phys. Oceanogr., 17, 2294-2317. 
1993. Effects of a concave bottom geometry on the upwelling-driven circulation in an abyssal ocean basin. J. Phys. Oceanogr., 23, 400-405.

Kawase, M. and D. Straub. 1991. Spinup of source driven circulation in an abyssal basin in the presence of bottom topography. J. Phys. Oceanogr., 21, 1501-1514.

Leaman, K. D. and J. E. Harris. 1990. On the average absolute transport of the Deep Western Boundary Currents east of Abaco Island, the Bahamas. J. Phys. Oceanogr., 20, 467-475.

McCartney, M. S. and R. A. Curry. 1993. Trans-Equatorial flow of Antarctic Bottom Water in the Western Atlantic Ocean: Abyssal geostrophy at the equator. J. Phys. Oceanogr., 23, 1264-1276.

Onken, R. 1992. Mesoscale upwelling and density finestructure in the seasonal thermocline-A dynamical model. J. Phys. Oceanogr., 22, 1257-1273.

Pedlosky, J. 1979. Geophysical Fluid Dynamics. Springer-Verlag, New York, 624 pp.

- 1980. The destabilization of shear flow by topography. J. Phys. Oceanogr., 10, 1877-1880. 1992. The baroclinic structure of the abyssal circulation. J. Phys. Oceanogr., 22, 652-659.

Pickart, R. S. 1992. Water mass components of the North Atlantic deep western boundary current. Deep-Sea Res., 39, 1553-1572.

Rhines, P. B. 1970. Edge-, bottom-, and Rossby waves in a rotating stratified fluid. Geophys. Fluid Dyn., 1, 273-302.

1989. Deep planetary circulation and topography: Simple models of mid-ocean flows. J. Phys. Oceanogr., 19, 1449-1470.

Rhines, P. B. and W. R. Holland. 1979. A theoretical discussion of eddy-driven mean flows. Dyn. Atmos. Oceans, 3, 289-325.

Smith, L. T. 1992. Numerical simulations of stratified rotating flow over finite amplitude topography. J. Phys. Oceanogr., 22, 686-696.

Speer, K., E. Tziperman and Y. Feliks. 1993. Topography and grounding in a simple bottom layer model. J. Geophys. Res., 98, 8547-8558.

Speer, K. G. and W. Zenk. 1993. The flow of Antarctic Bottom Water into the Brazil Basin. J. Phys. Oceanogr., 23, 2667-2682.

Stommel, H. and A. B. Arons. 1960. On the abyssal circulation of the world ocean-I. Stationary planetary flow patterns on a sphere. Deep-Sea Res., 6, 140-154.

Straub, D. N. and P. B. Rhines. 1990 . Effects of large-scale topography on abyssal circulation. J. Mar. Res., 48, 223-253.

Thompson, L. 1994. The effect of continental rises on the wind-driven ocean circulation. J. Phys. Oceanogr., (submitted).

Thompson, R. O. R. Y. and J. R. Luyten. 1976. Evidence for bottom-trapped topographic Rossby waves from single moorings. Deep-Sea Res., 23, 629-635. 